\title{
Personnel Characteristics of Maintenance Practice: A Case of High-Rise Office Buildings in Malaysia
}

\author{
Emma Marinie Ahmad Zawawi \\ Centre of Research \& Graduate Studies, Faculty of Architecture, Planning \& Surveying \\ University Technology MARA \\ 40450 Shah Alam, Malaysia \\ Tel: 6-03-5521-1518Ｅ-mail: emmamarinie@salam.uitm.edu.my \\ Syahrul Nizam Kamaruzzaman (Corresponding author) \\ Building Surveying Department, Faculty of Built Environment \\ University of Malaya \\ Lembah Pantai, 50603 Kuala Lumpur, Malaysia \\ Tel: 6-03-7967-6833 E-mail: syahrulnizam@um.edu.my
}

\begin{abstract}
An excellent practice of maintenance management is greatly needed to increase the life cycle of the property and to minimize unexpected breakdowns or deterioration effects. In this respect, the modern maintenance manager will have to rely as much on knowledge of the managerial and social sciences as on the traditional technique knowledge base of building construction and deterioration. Improper conduct and application of maintenance management procedure and systems may result in deteriorating the property itself. Therefore, the performance of the maintenance management operations have to be continuously reviewed and analysed in order to ascertain a high quality service. This study aims to present the personnel characteristics in the current practice of building maintenance management in Malaysia. Questionnaires are distributed to all maintenance personnel on selected buildings. These data are then analysed consequently to produce the in depth understanding of personnel characteristics in current building maintenance practice in Malaysia. This study believe to be valuable in identifying where the practice needed further attention and helped pin point problems areas within building maintenance management.
\end{abstract}

Keywords: Building maintenance, Personnel, High-rise offices, Malaysia

\section{Introduction}

Building maintenance management is a highly complex sphere of operations, involving the interaction between the technical, social, legal and fiscal determinants that govern the use of buildings (Francis et al, 2001). Most people do not realize that a building maintenance system contributes to the income of the company's owning or renting the building. It has become a part of a total performance approach, together with other factors such as productivity, quality, safety, and environment (Groote, 1995). Maintenance performance is generally hard to measure, as one should not only consider quantifiable parameters but also the quality of the performed maintenance and its organization (Armstrong, 1987).

As building in Malaysia is concerned, most buildings are maintained by their own staff instead of hiring contractors (Zawawi, 2006). Buildings such as hotels, hospitals and high-rise offices normally have their own maintenance department managed by a maintenance manager. Zawawi (2006), conducted a building satisfaction survey and found that most occupants considers that the maintenance serviced they received was not in the satisfied point. This involves issues such as lack of maintenance staff, unskilled workers, lack of tools and many more. Thus, this paper aims to assess and identify the personnel characteristics affecting building maintenance efficiency of building maintenance department in Malaysia. Maintenance personnel include maintenance staff or people responsible for maintenance job in the buildings.

\section{Data Gathering/Methodology}

Many of the possible subjects are not always in the office, as they are all moving about within the building, carrying out tasks. This makes interviewing problematic thus, questionnaire was chosen as the method of collecting data. This 
appears to be the most convenient way to obtain highest participation as people would be able to fill in the questionnaire during free time.

For this study, data are gathered from the entire maintenance individuals that are directly involve in maintenance works including repairing and supervising. As this involve all level of maintenance personnel, dual language, Malay and English was used, as this would help in providing better understanding of the questionnaires. The questionnaire was design for the maintenance personnel to fill in their details that includes data of academic qualifications, working experience, age, gender and so on. The maintenance personnel are divided into mechanical, electrical and electronic types. Likewise, the personnel are hierarchically group into engineer, superintendent and technician (Mjema, 2002). Five high-rise buildings located in Kuala Lumpur and Klang Valley were selected for this study. Based on the selected buildings, 76 questionnaires were distributed to all maintenance personnel.

\section{Building Description}

A summary of key building features is shown in the Table 1 . The number of storeys varies from ten to eighteen with a total gross floor area ranging from $6530 \mathrm{~m}^{2}$ to $18100 \mathrm{~m}^{2}$. These buildings are all modern type high-rise office buildings with sophisticated building services installed. All of these buildings operate approximately 8 hours to 10 hours a day.

\section{Discussions of Results}

\subsection{Gender and Working Experience}

From 76 respondents of maintenance staff in high-rise office buildings, males are more likely to be employed in the maintenance department rather than females (Figure 4). Only $7.9 \%$ of the respondents are found to be female. The study has also found that those females employee are most likely to be doing administrative work in the department, such as receiving calls for maintenance requests, filing and other similar tasks. The author strongly believed that having one or two such clerical persons in a maintenance department would be necessary. This is because most females are very familiar with paperwork, including typing, coding and so on.

Working experience is also one of the factors that affect the quality of maintenance system. The survey shown that from the entire 76 respondents in maintenance department, not many of them possesses a long working experience. Figure 2 shows that only $9.82 \%$ of them have 6 to 8 years working experience, and majority of the personnel obtain around 2 to 4 years experienced in that field $(44.70 \%)$. Even though, working experience does not give unswerving impact to the maintenance system but it does affect the quality of works. Peoples with more experience tend to do their work confidently and effectively while less experience peoples may need somebody to assist them.

\subsection{Academic Qualification}

Based on the survey data, most companies do not have full skilled maintenance personnel. Figure shows the percentage of academic qualification of maintenance people in the office buildings. Some of them are high-school leavers that do not posses the necessary skills to do maintenance job. A large number of them are back up with technical certificates as their education level. Only one-fourth of them have suitable qualification such as degrees or diplomas. Degree holders are the managers and those at a higher level. They are not involved in technical issues at all.

Technician and supervisors are among staffs with technical certificate and are considered as skilled staffs that fulfils the building maintenance requirements. SRP, SPM and STPM are those of school's passer, have no basic technical knowledge, and are considered as unskilled staff. Only a few of them have some working experience in this field. These are among the problems faced by most maintenance organisations in Malaysia. Hiring skilled maintenance personnel is difficult. In order to resolve this problem the Building Management Team should provide skill training to those staff without essential academic qualifications. The Stationery Office, (1994) has stated that it is the duty of an employer to ensure that his personnel have the necessary competency to do maintenance work. It is also the responsibility of the employer to provide employees with appropriate training if they are not competent enough to carry out tasks. Competency level should be emphasized because a maintenance department works closely with the building's control system. Moreover, unskilled staff could cause enormous damage to machines and equipment especially in a manufacturing plant, and therefore represent a high risk to the building. In view of this, staff must be carefully select for their knowledge and ability so that they are able to handle matters pertaining to plant equipment and other maintenance matters. Staff evaluation systems, staff motivation programmes and staff trainings are an effective ways to improve employees' maintenance skills and should be practiced more often to bring out the best out of them.

Faculty of Civil and Construction and Faculty of Architecture, Planning and Surveying of University of Technology MARA (UiTM, 2007) offers building services courses that provide students with knowledge and understanding on the principle of electrical and mechanical engineering. The courses emphasizes on the supervision of electrical system and different types of mechanical equipments that are commonly use in building. The operation and maintenance of the equipments are also taught to the students. Students will also learn the electrical wiring regulations and building service systems. Similar courses are also offered by two polytechnics in Malaysia but only at diploma levels. Some of the 
syllabuses are included in one or two subjects under architecture, building or real estate courses. Besides that, the National Vocational Training Council (NVTC, 2006) of Malaysia also provides and coordinates skill-training strategies and programmes to keep up with Malaysia's technological and economic development needs. The objectives are to establish a coordinated skill training system attuned to Malaysia's development goals and needs, to promote the development of skill training; and to certify skills competency. These facts clearly show that the standard of technical and skill training must be upgraded to fulfil the required standard. The Ministry of Education and related parties should consider ways to improve this situation. Introducing a technical skill programme or short-term courses on technical skills is one of the possible solutions.

\subsection{Flexibility of the Personnel}

Besides not having enough skilled maintenance staffs, most company also have lack number of maintenance staffs. Table 2 below list the number of staffs in the maintenance department in office buildings in Malaysia. The table shows that staffs are able to fix and repairs the entire maintenance request but will be over worked to maintain quite a large area. It is also important for every maintenance manager to study the minimum number of staff employed. This is to avoid overworked staff, which might affect the quality of the system. Chan et al., (2001) proposed the Manpower Utilisation Index to be used as an indicator to reflect how well the maintenance workforce has been utilised. This is useful in identifying whether the maintenance workforces is over, fully or under utilised, and for assessing the general productivity of the maintenance personnel. The size of building and the number of staff available are important factors that should be studied deeply.

Small simple buildings and large complex buildings might require different amount of maintenance work. The ratio of average request for repair daily or weekly to the number of maintenance work force would help management to predict whether the maintenance team is able to run the maintenance system effectively or not. The business function will dictate the maintenance needs. To ensure that an organisation achieves its business function with maximum efficiency, a clear understanding of maintenance need is required (Smith and Tate, 1998).

\subsection{Organization Structure}

Evaluation on maintenance personnel includes the way they communicate in the department. This would affect the efficiency of the maintenance system in the building. A good arrangement of organisation structure will help the maintenance department to manage the building without too much hassle. Most buildings in Malaysia have their organization structure but the problem it is not displayed for everyone to see. It is important for staffs to know their organization structure because it tells more about the responsibilities and provide staffs with the knowledge in seeking further assistance. An observation in most buildings in Malaysia found that most staffs are confused with its own position in the department and facing difficulties in finding the correct person to report. At the end, many unresolved requests and complaints has been store up. Maintenance staff should be clearly brief on the position, jobs, and responsibilities before any works can be executed.

Each maintenance personnel should know his or her responsibility in the department. Documented description of the job responsibility will help each person perform work better. A responsible job is one which the value of job outcomes is highly sensitive to the worker's input. A responsible worker is not closely monitored during the production process, but after the outcome of his work is evaluated, credits will be given for a well done job or blames if the job is poorly done. The degree of responsibility may be measured by the variation in the value of job outcomes over the feasible range of worker's effort. Management should prepare and explain the responsibilities of the staff due to their position in the department. This is to avoid any disputes between the employees over the jobs assigned. Therefore, when there is a request for maintenance work at a certain area, the person in-charge of that area will immediately take up the job.

Management of maintenance can also comprise more than the control activities associated with each item of equipment and can be addressed broadly under the headings of 'technical' and 'control' (BS 8210). Effective maintenance management minimized the cost associated with the non-availability of an engineering service (CIBSE, 2000). Maintenance manager must be able to manage the team as well as having sufficient knowledge of health and safety regulation and other requirements that are necessary to the departments. It is the responsibility to the manager to bring a satisfaction condition not only for the occupants but also to the staffs for not burden on overworked.

\section{Conclusions}

Building maintenance management is a highly complex sphere of operations, involving the interaction between the technical, social, legal and fiscal determinants that govern the use of buildings (Lee et al, 2001). An excellent practice of maintenance management is greatly needed to increase the life cycle of the property and to minimize unexpected breakdowns or deterioration effects. In this respect, the maintenance personnel will have to rely as much on knowledge of the managerial and social sciences as on the traditional technique knowledge base of building construction and deterioration (Smith, 1992). Improper conduct and application of maintenance management procedure and systems may result in deteriorating the property itself. 
Effective building maintenance can be achieved through a well-organized management, skilled maintenance personnel and a good organization structure (Smith, 2004). In this study the maintenance personnel requirements in Malaysia has been evaluated and the finding shows that many parties should be involved in enhancing the standard. The building Management Team as well as the Ministry of Education Malaysia and the Ministry of Human Resource should take note that prompt actions are really needed to build up the level of maintenance technology in Malaysia. The key factors described in this paper would hopefully be applied to provide guidance and references for better building maintenance management system for Malaysia.

\section{References}

Armstrong, J., (1987). "Maintaining Building Services, A guide for Manager." BSRIA, Technical Notes pp.17-131.

BSI, (1986). BS 8210: Guide to Building Maintenance Management. British Standards Institute, UK.

CIBSE (2000), Guide to ownership, operation and maintenance of building services, Chartered Institute of Building Services, UK.

El-Haram, M.A \& Horner, M.W. (2002) Factors affecting housing maintenance cost. Journal of Quality in Maintenance Engineering, Vol. 8, No. 2, pp 115-123.

Francis W.H and Yik, W.L, Lee, C.K.Ng (2002) Building Energy efficiency and the remuneration of operation and maintenance personnel. Facilities, Vol.20, pp 406-413.

Grooted, P. De. (1995). Maintenance Performance Analysis: A Practical Approach. Journal of Quality in Maintenance Engineering Vol.1, No.2, pp 4-24.

K.T. Chan., R.H.K. Lee, and J. Burnett.(2001) Maintenance Performance : A case study. Facilities Vol.19, No.13/14, pp 494-503.

M. H. Smith. (1992). 'Decisions in Maintenance', Technical Note TN 14/92, BSRIA.

Mjema, E.A.M. (2002). An analysis of personnel capacity requirement in the Maintenance department by using a simulation method, Journal of Quality Maintenance, Vol.8, pp. 253-273.

NVTC, (2006) National Vocational Training Council of Malaysia. [Online] Available: http://www.nvtc.gov.my (July 15, 2007)

Richard A. Smith. (2004). 'How to Develop and Implement A successful Maintenance Skills Training Program'. [Online] Available: www.plantmaintenance.com/articles/Assessing_Maintenance_Training_Needs.pdf (August 27, 2007)

Smith, M. and Tate, A. (1998). 'Maintenance Programme Set-Up', Application Guide AG 1/98, BSRIA

The Stationery Office, (1994). The Construction (Design and Management) Regulation: Statutory Instrument 199,4 No. 3140, London.

UiTM, (2007). UiTM Prospectus, University Technology MARA, Malaysia.

Zawawi, E.M.A. (2006). The development of guidelines for the Management of Building Maintenance in Malaysia. The University of Manchester, UK. [Unpublished thesis]

Table 1. Details of high-rise office buildings

\begin{tabular}{|c|c|c|c|}
\hline Building & Building Location & Building Gross Floor Area & No. of Maintenance \\
\hline Building A & Shah Alam, Selangor & 18100 & 40 \\
\hline Building B & Shah Alam, Selangor & 10934 & 5 \\
\hline Building C & Subang, Selangor & 6530 & 4 \\
\hline Building D & Kuala Lumpur & 12300 & 6 \\
\hline Building E & Kuala Lumpur & 14000 & 21 \\
\hline
\end{tabular}




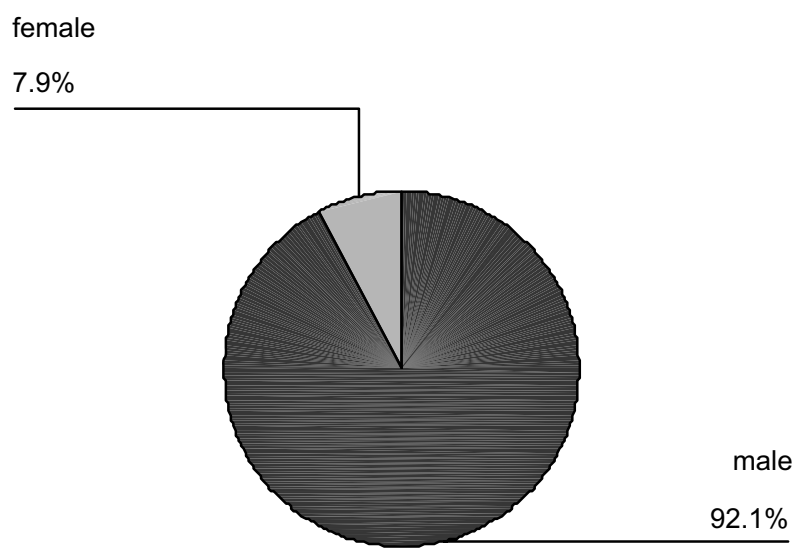

Figure 1. Staff Gender

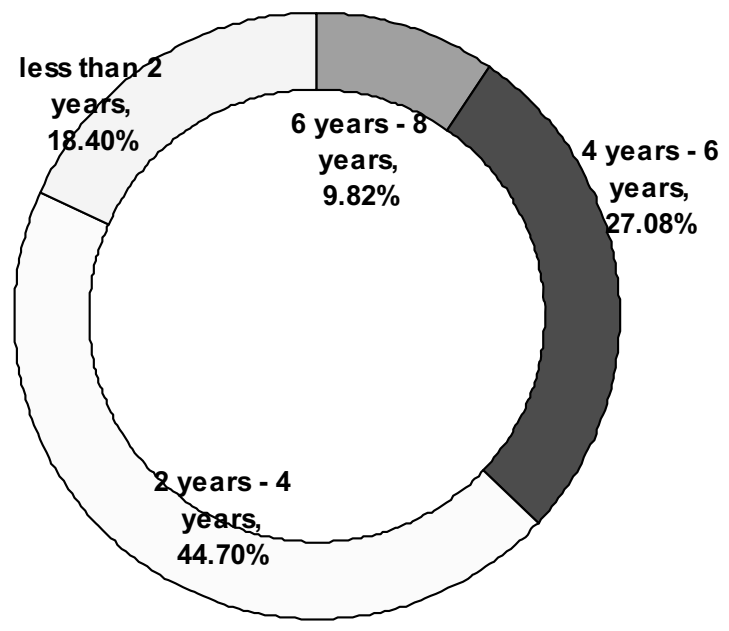

Figure 2. Job experience

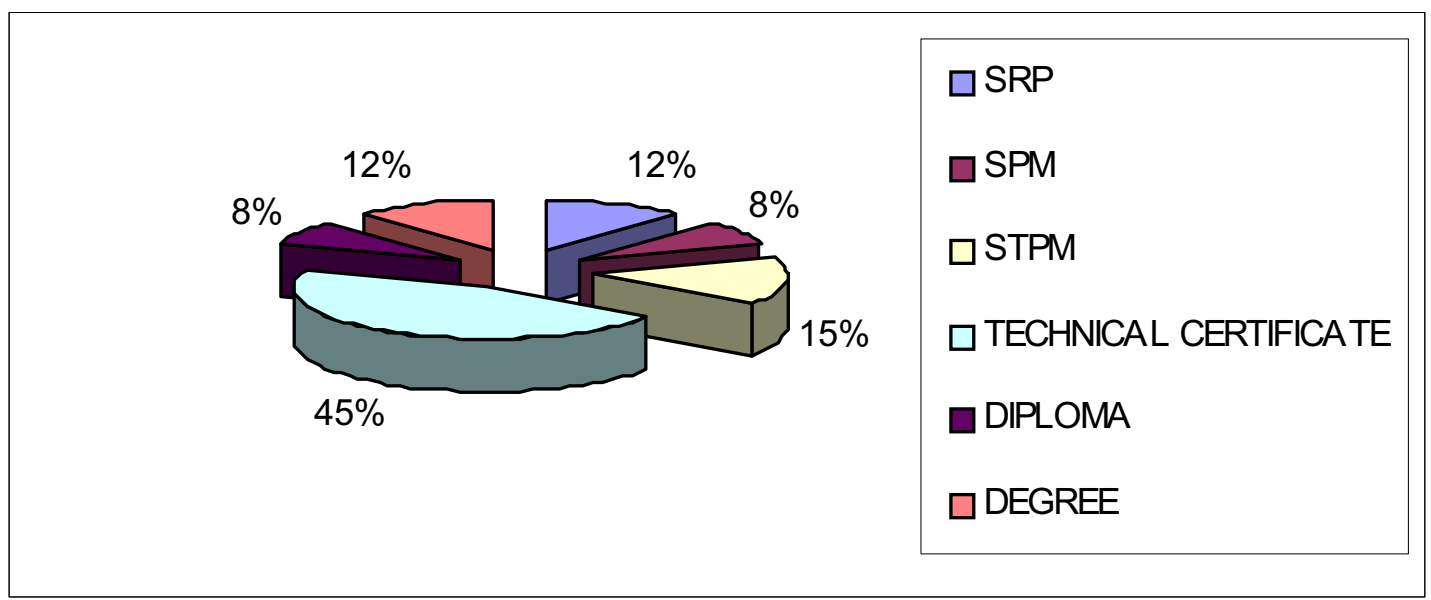

Figure 3. Percentage of academic qualification of maintenance people in office buildings 


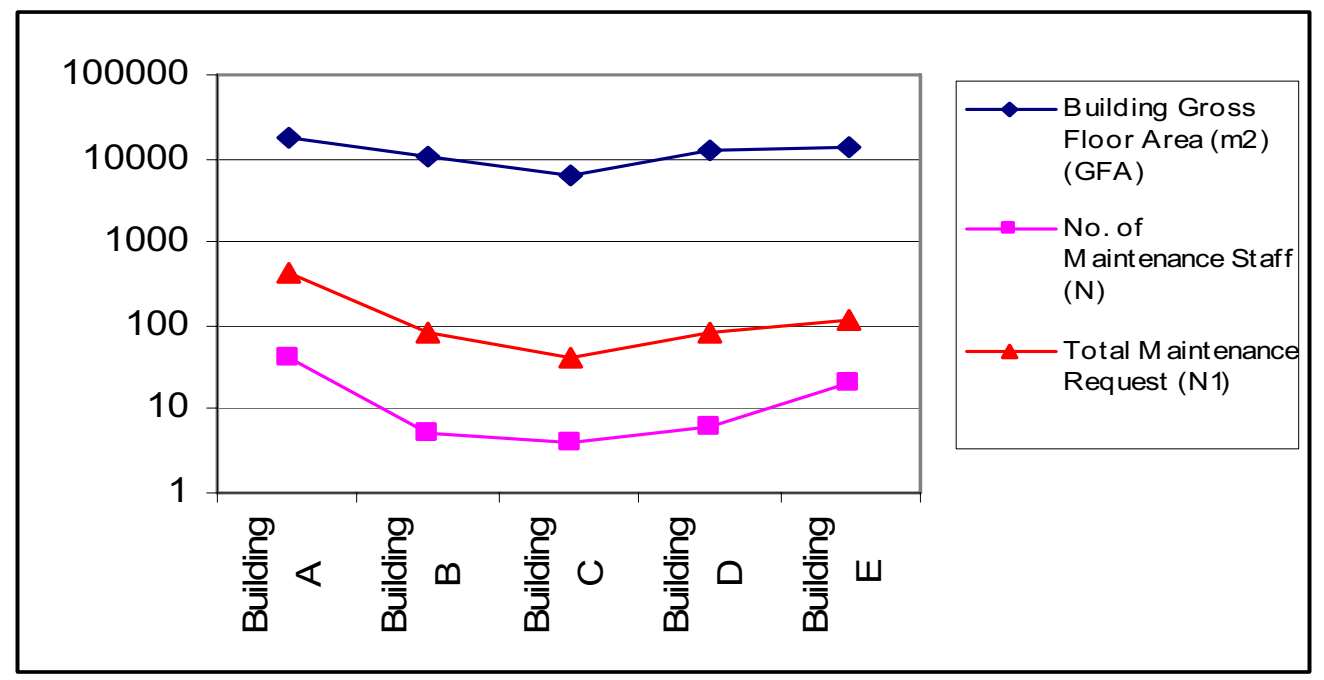

Figure 4. Building size, number of staff and requests demand

\section{$\mathrm{MUI}=\quad$ Maintenance hours spent on maintenance works in a period Total maintenance hours available for maintenance in the same period.}

Equation 1. Manpower Utilisation Index (MUI), (Chan, et al., 2001). 